\title{
Writing Across the Curriculum in a Human Physiology Class to Build Upon and Expand Content Knowledge
}

\author{
By Aaron Bunker* \\ Jeremy Schnieder ${ }^{\dagger}$
}

Leading scientific organizations, like the American Association for the Advancement of Science, have called for innovative approaches to student learning that incorporate "real-world examples". Drawing on writing-to-learn theory, innovative writing projects can be used when they build upon writing skills acquired from other disciplines and use creative writing in order to improve content comprehension. This paper draws on the use of narrative writing in a college-level, human physiology course to show the benefits of alternative types of writing assignments. The paper provides the creative narrative assignment learning objectives, rubrics, and examples of student work. This paper also demonstrates how to transform a conventional physiology writing project into an innovative multidisciplinary writing across the curriculum (WAC) project. Specific student writing examples are provided in the paper to show how the students interacted with the course content in a playful way as they drew from writing skills learned in other classes.

Keywords: creative narrative, writing across the curriculum, physiology

\section{Once Upon a Time in Biology Class}

To believe that writing is not connected to virtually any discipline would be a clear misrepresentation of the work done by the scholars and teachers in that field. Traditional disciplinary genres, such as lab reports, mathematical proofs, and other STEM-based genres, are an important part of many classrooms; after all, an important part of teaching disciplinary values, thought patterns, and communicative practices comes through the genres themselves. For a student to be educated in a discipline, or at least show an understanding of that discipline, an awareness of disciplinary communication is necessary. It is for this reason that STEM-based genres find their way into the curriculum.

Traditional disciplinary writing, though important, does not have to be the only writing in the STEM classroom. While discipline specific types of writing are an important part of major curricula, alternative forms of writing can still play a role. Students (and sometimes faculty), may be surprised by the way writing can be used, and a carefully designed creative writing assignment will

${ }^{*}$ Assistant Professor, Morningside College, USA.
${ }^{\dagger}$ Assistant Professor, Morningside College, USA. 
not only enliven the classroom, it will also serve as a powerful way to encourage meaningful connections with content, a deeper understanding of concepts, and the ability to discuss disciplinary concepts with a nondisciplinary audience.

This is the case of the writing used in Aaron Bunker's Human Physiology classroom. The traditional disciplinary genres, such as lab reports and other traditional scientific genres, are used along with alternative styles that encourage students to approach the content in a creative manner. Thus, in this paper, we will attempt to illustrate the place that creative narratives can hold in both the classroom and in sound pedagogical practices. We will also provide specific examples of the work done by Bunker's students to show how they came to interact with the content in a playful way as they draw from writing skills learned in other classes. In essence, Bunker's assignment epitomizes writing across the curriculum (WAC) and its benefits.

\section{Writing and the Use of Narratives in Learning Biology}

In 2011 the American Association for the Advancement of Science (AAAS), a prestigious international organization leading the charge in "advancing science for the benefit of all people" published a comprehensive report containing recommendations for institutional change in baccalaureate biology education (Vision and Change in Undergraduate Biology Education, 2011). One of the major recommendations made by AAAS entailed the use of innovative pedagogy and varied assessment in a student-centered biology classroom (Vision and Change in Undergraduate Biology Education, p. 21-30). According to AAAS, this would entail intentionally designing assignments so they "Relate abstracts concepts in biology to real-world examples on a regular basis, and make biology relevant by presenting problems in a real-life context". While this could take many forms, writing in the biological sciences is a wellknown student-centered pedagogical approach to assessing student comprehension of biology content (Moore, 1994; Keys, 1999). Balgopal and Wallace (2013) make the case that writing to learn is a very useful tool for doing just this. They continue to argue that it is underutilized. Randy Moore (1994) and Carolyn Keys (1999) have also written articles where they argue the need for more writing to learn in biology. They believe that writing increases student interaction with, and understanding and reflection of the content; be it writing through a variety of short assignments (Moore, 1994) or writing through scientific investigations/experiments (Keys, 1999). Moore argues for the inclusion of writing with a focus evaluation of ideas, concepts, and writing from the field. Moore also uses traditional journaling techniques. While Moore and Keys' arguments are well grounded, the need for innovative biology writing assignments (as recommended by the AAAS) that intentionally buildupon writing skills acquired from other disciplines and that intentionally allow for creative thinking in order to improve content comprehension are lacking from the Moore and Keys recommendations. 
The use of assignments in biology that entail creative thinking for learning biological concepts is not a new pedagogical approach. Willis Kirkland (1997) describes a creative writing assignment for a non-majors Human Biology course where students are to write a very short story based off detailed scenarios he provides the students that relate to the current content of the course. Several of these short writings are assigned to prepare the students for each upcoming exam, but do not involve much in terms of focusing on the writing process (i.e. revising and multiple drafts). Keith Killingbeck (2006) tells a success story of creative writing using multiple genres in a field botany class and describes the amazing writing students can do when given the freedom to write creatively. Much like Kirkland's assignment, Killingbeck's assignment does not involve much focus on the writing process (i.e. revising and going through multiple drafts). However, both authors implicitly note the importance of modeling the writing themselves for the students before allowing students to begin the assignment. Steglich (2006) also discusses a creative writing assignment similar to Kirkland and Killingbeck, but the learning outcomes were more about "...produc[ing] and reinforc[ing] specific attitudes about the course and the subject" than mastering content or improving writing skills.

Creativity in the form of a narrative is also becoming more widely used in biology classes at both baccalaureate and post-baccalaureate levels for varied pedagogical reasons. For instance, in medical schools, the use of the personal narrative is at the forefront of future physician education. Several authors argue that use of the personal narrative engages students in the material by making it personal and therefore real world for them (Charon, 2001; Charon, 2012; Nowaczyk, 2012). The authors also argue that this approach to physician education shows students that science is not strictly rational, neutral, and objective; an important perspective to develop when practicing medicine. However, narratives in these articles refer to narratives that the students read, not write themselves, to comprehend the science.

Intentional use of the narrative for writing to learn in science classes at the baccalaureate level is just in the early stages of fruition. Rich, Miller, and DeTora (2011) provide examples of success in using oral narration to learn in the physical sciences and engineering, and as way to encourage student metacognition of their learning. Rich, Miller, and DeTora (2011) found that through the use of oral narration students "were consistently more successful in problem-solving, even if they did not apply these skills to all problems". Similarly, Preston Feden (2012) had his baccalaureate students in an interdisciplinary biology course read and tell stories to learn various biological and historical concepts. He found that students improved their responses to a big-issue, critical thinking question related to the course content in a more elaborate and factually supported way by the semester's end.

All of the previously discussed articles offer sound pedagogical approaches that employ creativity and narration to improve student mastering of biological content. However, they were not designed to build-upon writing 
skills acquired from other disciplines nor do they use creative writing in order to improve content comprehension. Therefore innovative writing assignments designed to improve both writing skills and understanding of biological content are needed to address one of the major recommendations made by AAAS for institutional change in baccalaureate biology education.

\section{Writing to Learn}

Clearly there is a place for writing in the STEM setting, particularly the biology classroom, and the student centered, real-life pedagogical approach called for by the AAAS is powerful. In his seminal piece What the Best College Teachers Do, Ken Bain (2004) notes that the participants in his study were able to establish an environment in which "...people learn by confronting intriguing, beautiful, or important problems, authentic tasks that will challenge them to grapple with ideas, rethink their assumptions, and examine their mental models of reality". While there are many ways of doing this, writing to learn has been noted as a means of engaging students in this way. Susan McLeod (Tate, Rupiper, \& Schick, 2001) writes that writing to learn is:

[first] student centered. College faculty who focus on and are concerned about their students' learning are those who pick up WAC techniques and use them successfully; they are quick to see the value of assignments [...] that promote active learning and critical thinking. Second, it is reflective. These exploratory writing assignments are all ones that provide a feedback loop to the teacher as to the progress of student learning, allowing her or him to adjust teaching accordingly. It also takes teacher out of role of judge for awhile, allowing her to play the role of coach (p. 57)

The awareness of its potential in the classroom, though, has been noted since the 1970s as part of the writing across the curriculum movement. In this way, writing to learn clearly aligns with the needs outlined by AAAS.

The WAC movement embraced the power of writing and low-stakes writing as a way to encourage a meaningful interaction with content in the 1970s. Janet Emig's (1977) seminal piece "Writing as a Mode of Learning" laid the foundation by illustrating the ways that writing encourages students to interact with information in several ways. Early in the movement scholars began to discuss the ways that "writing to learn" could supplement traditional writing assignments. James Britton (1975) discussed the ways that writing could be expressive or could focus on a teacher/student transactional relationship. Emig's earlier work The Composing Process of Twelfth Graders (1971) showed that students would incorporate the writing practices many teachers hoped for, such as drafting and revising, in their personal writing. Even as scholars and teachers seek to incorporate writing in the disciplines and to further emphasize the ways that writing is used and taught in specific 
settings, writing to learn has maintained its place in the classroom up to present day as is evident in the work of scholars such as Balgopal and Wallace (2013) and many many others.

There are several reasons why writing assignments of this nature benefit students. Often writing to learn is associated with journaling. Toby Fullwiler (1980) made a strong case for this as part of the WAC movement and Russek (1998) discussed it as part of mathematics classroom. However, writing to learn provides a place for students to "play" or interact with the content in a new way. Furthermore, the assignments push students away from a mode in which they merely give back the same content provided by instructors. Writing to learn also encourages an active interaction with content as noted in Bean's (2011) well-known and practical guide to writing to learn. As the Kirkland (1997) and Killingbeck (2006) articles illustrate there are examples of the use of creative genres in biology. Kirkland discusses the use of analogies that lead to creative pieces. Killingbeck discusses the use mnemonic devices for content and terms. Similarly, uses of poetry are available by Meg Petersen in chemistry (2001) and Patrick Bahls (2012) in the mathematical science. Young (2003) explains that when people write poetically and express their ideas and values about science in nonscientific language, freedom from scientific discourse creates opportunities to make personal connections to what they are writing about. Writers are free to invent their own poetic language in order to find fresh insights into their learning as well as imaginative and innovative ways to communicate with others. Writers take the unfamiliar knowledge they are learning in class and attempt to integrate the new knowledge into what they already know - and thereby assimilate the new, or enrich it, or critique it. The same can be said for creative narratives. While as Moore (1994) notes that "The form of scientific writing is so vital that no paper can be published that does not closely follow the accepted format", creative narratives allow students the opportunity to break away from this form to engage the content in very different ways in order to become more familiar with the content.

The use of narrative and storytelling may not be a part of all classes, but it has been argued to be a part human interaction. Willingham (2009) writes, "the human mind seems exquisitely tuned to understand and remember stories - so much so that psychologists sometimes refer to stories as "psychologically privileged" meaning they are treated differently in memory than other materials" ( $\mathrm{pp}$ 66-7). Willingham notes the advantages of stories in communication as part of his discussion of using them to communicate with students. Specifically, he acknowledges that since stories have an easily identified and comfortable structure and are engaging and memorable (pp 678 ). It makes sense, then, that the benefits stories have in communicating with students are the same benefits that can come as students communicate with instructors and each other through stories. In essence, they interact with the information in a way that is comfortable and accessible, which increases what they remember. It is clear just why this can be such an effective method of writing to learn. 


\section{Teaching in the Narrative}

In light of the major recommendations made by the AAAS that called for major reform in baccalaureate biology education and the importance of using writing to learn and other real-life pedagogical approaches, Bunker set out to design a creative writing project emphasizing content comprehension that also involved the students making real-life connections with the content. He created the assignment for his Human Physiology course, which is primarily taken during the spring semester by second semester freshman students (typically about 40 students) that are preparing to enter the nursing program. In the course students develop an understanding of how the major body systems work in both normal and some disease states. While the course is very content driven, the content is mastered through extensive problem-solving and writingto-learn activities that are connected to real-life through narratives.

As Willingham (2009) suggested, narrative has a powerful effect on the classroom as it encourages a greater level of engagement. Bunker's pedagogical approach to the entire course is very narrative in nature and he does this in order to continuously model the use of a narrative as a means of interacting with content/technical knowledge for the students. This pedagogical approach entails using a central character and stories relating to the character for the following: physiological content and in class problem solving, assigned homework problems or writing activities, and the central character appears in all the exams, which are also somewhat narrative in format. Consequently, throughout the entire semester students experience a narrative of the how the human body works both during class meetings and through all the formal assessment related to the class. By doing this Bunker again, models how narrative can be used to teach and learn about science, while at the same time connecting the content to real-life examples viz-a-vis the narrative approach.

\section{Narrative and Classroom Practice}

To work towards achieving these goals, Bunker designed the creative writing project to align with the first course objective where after taking the course students should: have gained an understanding of how the body maintains homeostasis via the use of control systems under normal and various pathophysiological (disease) conditions. The writing project was initially a traditional report on a disease where the students would learn more about a body system disease than what would normally (if at all) be covered in the class. The initial writing project's major requirements were the following:

1. Brief background/overview of the normal physiology of affected organ system.

2. Disease pathophysiology- how is the normal physiological function described in item \#1 altered by the disease?

3. Causes and symptoms - how can one acquire the disease and what 
signs of the disease do the physicians/nurses often observe?

4. Diagnostic procedures and/or tests for the disease-what is done to enable the physicians/nurses to diagnose the disease?

5. Treatments and preventive measures-(if any, if not, discuss why not) what do the physicians/nurses tell their patients in terms of prevention and treatment?

Upon reflection, Bunker decided to change these initial requirements after realizing that a large majority of the students in this class had just finished the First Year Seminar (FYS) course the previous fall semester, which is Morningside College's equivalent of college composition. The FYS course introduces students to basic academic skills, such as careful reading, thoughtful writing, and critical thinking. After discovering that the students had just finished the FYS course, he redesigned the writing project so it: 1) contained intentional cross disciplinary connections to capitalize on the skills acquired in the FYS course and 2) was a creative narrative writing project. As such he rewrote the major requirements accordingly:

1. Brief background/overview of the normal physiology of the main character's organ system.

2. Disease pathophysiology- how is the normal physiological function described in item \#1 altered by the disease in the main character?

3. Causes and symptoms - how did the main character get the disease and what signs of the disease did the physicians/nurses observe?

4. Diagnostic procedures and/or tests for the disease-what was done to the main character to enable the physicians/nurses to diagnose the main character with their disease?

5. Treatments and preventive measures-(if any, if not, discuss why not) what did the physicians/nurses tell the main character about their disease in terms of prevention and treatment?

Thus, one can easily imagine how these very small additions to the requirements lead to a very different writing experience for the students given the type of writing now required. Bunker also provided a rationale for this project wherein he described that most of the reasons for even taking a human physiology course in their nursing program is to know how the body functions in healthy people. He continued to tell them how this project would expose them to how the body functions change in diseased people, thereby expanding upon what the students learn in class and connect the course content to real-life scenarios where knowing physiology is important. He didn't go into the specifics of creative writing or even of narrative writing, instead he merely told them to have fun, use humor, and be creative! Bunker did, however, provide an example narrative writing of what he would write if he were a student. This modeled well for the students his expectations in writing conventions and content comprehension expectations. 
The project itself consisted of a rough draft worth points that Bunker reviewed and for which he provided extensive feedback. In addition to the creative writing requirements listed above, the project asked the students to use at least two images or diagrams in the paper to illustrate the disease and changes in body physiology, and to cite from where the image was taken. Furthermore, in connection with the FYS course, students were required to cite 3 articles, both in the text and in a references list, using American Psychology Association (APA) format. Both the process of writing narrative/descriptive papers and learning how to cite sources are major components of the FYS course, so these requirements in the project made intentional cross-disciplinary connections between biology and composition classes.

The end products were very impressive in how the students demonstrated their newly acquired writing skills from FYS, and in a very, very creative way. For example, one student's narrative was entitled "Iron Man's Disease", and centered on a character named "Tony" who in the story found out he had hemochromatosis (i.e.-excessively high levels of iron in his blood). Here is an excerpt from the narrative where a "Dr. Banner" runs tests on Tony and tells him about his disease:

The first test was called a Serum transferrin saturation test that measures the amount of iron bound to transferrin, which is a protein that carries iron in the blood. Transferrin saturation values greater than 45 percent are considered too high. The second test was called Serum ferritin, which measures the amount of iron stored in the liver.

As soon as the doctor's lab obtained the blood test results Tony went to the doctor's office. Dr. Banner said that if the Serum Ferritin value was greater than $300 \mathrm{ng} / \mathrm{mL}$ it means there is too much iron in the body. Tony's result was $1050 \mathrm{ng} / \mathrm{mL}$ and Dr. Banner told Tony his diagnosis.

"Tony, the iron levels in your blood are extremely high, this means that you have a disease that is called Hemochromatosis."

Tony did not know what that weird disease was so he was scared and confused. Dr. Banner explained it to Tony:

"Hepcidin, a liver-derived peptide, is the critical control mechanism for iron absorption. Hepcidin is normally up-regulated when iron stores are elevated and, through its inhibitory effect on ferroportin (which participates in iron absorption), it prevents excessive iron absorption and storage in normal people. The mechanism for iron overloads in both HFE and non-HFE (genes) hemochromatosis is increased iron absorption from the gastrointestinal (GI) tract, leading to chronic deposition of iron in the tissues." (Rivera, 2013, shown in figure 1).

This part of the narrative also contained a reference at the end to a 
figure/diagram used to help depict some of the disease description for the reader, a requirement of the paper mentioned earlier. This paper was particularly creative through its use of pop-culture/comic book movie characters to narrate a story about a disease. Additionally, the paper illustrates important content from the course such as the function of iron in the body and the importance of the liver in normal absorptive processes.

Yet another student demonstrated creativity in their narrative writing when they wrote a piece entitled "The Case of Abcde and Roy" that centered around a princess (Abcde, pronounced Ab-Sa-Dee) and her father King Roy who discovers he has coronary artery disease. The section excerpted below serves as a good demonstration of how the students creativity wove how coronary artery disease alters the physiology of the arteries into a narrative story:

One night during an emotional talk about Abcde's mother, Roy started complaining of chest pains. Immediately, Abcde called for the best doctor around, because she was not going to lose the one parent she still had left. Abcde knew that there was a history of coronary artery disease on her dad's side, so she did not waste anytime calling the doctor. The best doctor in the kingdom of Everafter was La-a (La Dash A). Dr. La-a was not only the best doctor in the kingdom, but also the best cardiologist in the land. When Roy and Abcde first arrived at the doctor's office the nurses took Roy's vitals. His blood pressure was high at 148/98mm Ho his heart rate was fast at 90bpm, and he had a temperature of $98.8^{\circ} \mathrm{F}$. Once the doctor had done a complete examination and obtained a medical history, she thought she had a good idea of what was going on with Roy.

The doctor went on to explain to Roy that CAD is caused by hardening of the coronary arteries on the surface of the heart, also known as atherosclerosis. He told Roy that atherosclerosis is the most common form of arteriosclerosis (hardening of arteries) and is responsible for about 50\% of the deaths developed in the world (Fox, 2009). Dr. La-a continued to describe to Roy how the once smooth and flexible arteries build up fatty deposits or plaques on their inside lining (See Figure 2) and that this narrowing of the arteries cause decreased blood flow to and from the heart. Dr. La-a also said that Roy has high blood pressure because his arteries are so narrow that the heart has to work much harder to pump the blood to the lungs and the rest of the body.

The two excerpts above serve as only a few examples of the many creative and physiologically accurate narratives that were turned in by the students. When students engaged in this writing project they were exposed to a great deal of new factual knowledge about how the body works in a diseased state, diagnostic procedures relating to the disease, and common treatments. Moreover, the students built upon writing skills acquired from other disciplines and used creative writing in order to improve their content comprehension. 


\section{Narrative Writing Project Evaluation}

These and the many other narratives students wrote enabled the students to work with the content knowledge in very different ways. Specifically, this assignment illustrates how an alternative, formative writing assignment can use creativity to fully develop the goals of the AAAS regarding innovative pedagogy that connects content to real-life. For instance, as demonstrated by the student narrative excerpts one can see the very student-centered nature of the assignment in the freedom they had to create their own story and make reallife connections, sometimes even on diseases of their own or of family members. No directions were provided to the students over how to create a narrative, only Bunker's modeling the narrative for them throughout the semester. So the creativity seen in the excerpts above was entirely left up to them. Through this assignment the classroom took on an even more student centered position, much like Susan McLeod (Tate, Rupiper, \& Schick, 2001) suggested, and through play, students made deeper connections noted by proponents of creative writing to learn styles. Furthermore, though writing to learn has been employed in the STEM setting, and even in a creative manner, this approach models the ways that biology can be fun through the continual narrative that is a part of the class while making numerous real-life connections. Consequently this type of assessment for student learning was quite varied compared to the conventional approaches that could have been taken for writing to learn in the biological sciences. Moreover, this writing approach made the content less intimidating, more engaging, and allowed for creative thinking. Student written comments revealed success how in the narrative writing project enabled students to become more engaged with the content and think creatively. As an example, one student noted:

I thought the project was more fun than trying to write a traditional essay. I liked the way it could incorporate learning and creativity into one thing. I also tried to have a lot of fun with it while trying to provide a lot of cool information I found while the learning occurred. Great idea as far as I'm concerned!

Likewise, the assignment enabled deeper connections and more meaningful understanding of concepts, as is also evident in student written feedback:

Overall, I would say that I enjoyed the project very much. It was challenging and forced you to really take a look into the selected disease. The project makes you take the disease and put it into a clinical setting and truly think of all the factors that go along with it. This made me really understand what I was reading about this disease. ... I really liked doing this assignment because it was different from just traditional research projects. It challenged me and made me think outside the box. 
Evidence for the success of the narrative writing approach was most apparent in the course evaluation forms used to assess student ratings of instruction for the course. At the semester's end, the institution collected data for course evaluations forms anonymously from each student in the course. While the course evaluation forms addressed the course and instructor as whole, there were two specific items relevant to the narrative writing project: "Demonstrated the importance and significance of the subject matter" and "Gave projects, tests, or assignments that required original or creative thinking". Both of these items increased from $76 \%$ to $87 \%$ of the students rating a 4 or 5 out of 5 (with 5 being the highest on a Likert scale) from a year when this narrative writing wasn't being used to the first year when it was used.

In essence, students were able to forget they were learning about biology and they found ways to talk about the human body. These assignments were definitely not like the serious narratives used in other settings. Their silliness and creativeness gave students permission to approach the content in a different way that actually required them to have a deep understanding of the content in order to use it correctly.

\section{Conclusions}

Future iterations of this assignment will include reflection with the narrative assignment. In these reflections students will be asked to explain the scientific concepts they chose as well as how they adapted those concepts for the narrative. These reflections could be paired with an explanation of the same concepts by a control group to see if there is indeed a deeper understanding of the information as it is adapted to the new form. Further assessment of added learning would entail asking students to take even more creative steps and explaining their work. Finally, we could assess students in STEM majors longitudinally to ascertain what these students remember in later courses, which would enable a deeper understanding of the long-lasting effects of these teaching techniques.

Narration and use of the narrative approach should not necessarily be the explicit nor the dominant pedagogical approach to student mastery of biology or any other STEM area content. The biological sciences and other STEM areas have their own empirical process that students should understand and appreciate. However, narratives can supplement and enhance the scientific learning experience when used in innovative and intentionally constructed ways. As this approach illustrates, sometimes a little "once upon a time" is just what the STEM classroom needs.

\section{Acknowledgments}


Our thanks to the Athens Institute for Education and Research for allowing us to modify templates they had developed. Thanks the Gleason Fund for additional funding to attend the ATINER Annual Conference on Biology. Thanks as well to the colleagues, friends, and editors that have helped in the revision process.

\section{References}

Bahls, P. (2012). Student writing in the quantitative disciplines: a guide for college faculty. San Francisco: Jossey-Bass.

Bain, K. (2004). What the best college teachers do. Cambridge, Mass.: Harvard University Press.

Balgopal, M., \& Wallace, A. (2013). Writing-to-Learn, Writing-to Communicate, \& Scientific Literacy. The American Biology Teacher, 75(3), 170-175. DOI= http://dx.doi.org/10.1525/abt.2013.75.3.5.

Bean, J. C. (2011). Engaging ideas: the professor's guide to integrating writing, critical thinking, and active learning in the classroom (2nd ed.). San Francisco: Jossey-Bass.

Britton, J. N. (1975). The development of writing abilities (11-18). London: Macmillan.

Charon, R. (2001). The patient-physician relationship. Narrative medicine: a model for empathy, reflection, profession, and trust. Journal of the American Medical Association, 286(15), 1897-1902. DOI=10.1001/jama.286.15.1897.

Charon, R. (2012). At the membranes of care: stories in narrative medicine. Academic Medicine, 87(3), 342-347. DOI= 10.1097/ACM.0b013e3182446fbb.

Emig, J. (1977). Writing as a mode of learning. College Composition and Communication, 28(2), 122-128. DOI=10.2307/356095.

Emig, J. A. (1971). The composing processes of twelfth graders. Urbana, Ill.: National Council of Teachers of English.

Feden, P. D. (2012). Teaching without telling: contemporary pedagogical theory put into practice. Journal on Excellence in College Teaching, 23(2), 5-8.

Fulwiler, T. (1980). Journals across the disciplines. The English Journal, 69(9), 14-19.

Keys, C. W. (1999). Revitalizing instruction in scientific genres: connecting knowledge production with writing to learn in science. Science Education, 83(2), 115-130. $\quad$ DOI $=\quad 10.1002 /($ SICI $) 1098-237 X(199903) 83: 2<115:: A I D-$ SCE2>3.0.CO;2-Q.

Killingbeck, K. (2006). Field botany and creative writing. Journal of College Science Teaching, 35(7), 26-28.

Kirkland, W. L. (1997). Teaching biology through creative writing. Journal of College Science Teaching, 26(4), 277-279.

Moore, R. (1994). Writing as a tool for learning biology. BioScience, 44(9), 613.

Nowaczyk, M. J. (2012). Narrative medicine in clinical genetics practice. American Journal of Medical Genetics, 158A(8), 1941-1947. DOI=10.1002/ajmg.a.35482.

Petersen, M. (2001). The atomic weight of metaphor: writing poetry across the curriculum. Writing Across the Curriculum, 12, 97-100.

Rich, J., Miller, D., \& DeTora, L. (2011). From concept to application: student narratives of problem-solving as a basis for writing assignments in science classes. Across the Disciplines, 8(1), 6-8.

Russek, B. (1998). Writing to learn in mathematics. Writing Across the Curriculum, 9 , 
36-45.

Steglich, C. S. (2006). A writing assignment that changes attitudes in biology classes. The American Biology Teacher, 62(2), 98-101. DOI= http://dx.doi.org/10.1662/0002-7685(2000)062[0098:AWATCA]2.0.CO;2.

Tate, G., Rupiper, A., \& Schick, K. (2001). The pedagogy of writing across the curriculum. A guide to composition pedagogies (pp. 149-164). New York: Oxford University Press.

Vision and Change in Undergraduate Biology Education. (2011). Vision and Change in Undergraduate Biology Education Transforming Undergraduate Education in Biology Mobilizing the Community for Change Comments. Retrieved February 9, 2014, from http://visionandchange.org/.

Willingham, D. T. (2009). Why don't students like school?: a cognitive scientist answers questions about how the mind works and what it means for the classroom. San Francisco, CA: Jossey-Bass.

Young, A. (2003). Writing across and against the curriculum. College Composition and Communication, 54(3), 472-485. 
